\title{
Components of Appreciative
}

\section{Functioning: A Thematic Analysis of Relevant Literature and Content Analysis of Existing Measurement Scales}

\author{
Reuben D Rusk*, Dianne A Vella-Brodrick and Lea Waters
}

\section{*Correspondence:}

rrusk@student.unimelb.

edu.au

Melbourne Graduate School

of Education, University

of Melbourne, 100 Leicester

Street, Parkville, VIC 3010,

Australia (c) 2015 Rusk et al. This article is distributed under the terms of the Creative Commons Attribution 4.0 International License (http:// creativecommons.org/licenses/by/4.0/), which permits unrestricted use, distribution, and reproduction in any medium, provided you give appropriate credit to the original author(s) and the source, provide a link to the Creative Commons license, and indicate if changes were made.

\begin{abstract}
Background: Growing evidence is linking gratitude with well-being, yet insufficient scholarly attention has been given to how it is defined, understood and measured. To address this issue, gratitude and gratefulness can be usefully distinguished as two types of appreciative functioning. Applying complex dynamic systems theory, appreciative functioning is conceptualised as a pattern of cognition and behaviour that involves the interaction of awareness, comprehension, emotions, goals, and relationships. The aim of the current work was to explore this system of appreciative functioning in greater detail.
\end{abstract}

Methods: A deductive thematic analysis of relevant literature was performed in Study 1 to identify psychological and social components of appreciative functioning within an empirically-based systems framework. Study 2 used a content analysis methodology to quantify the extent to which the components identified in Study 1 are covered by existing scales that assess gratitude and gratefulness.

Results: Study 1 identified 32 theoretical components within five overarching domains that comprise the system of appreciative functioning. Gratefulness and gratitude were found to involve many components, with some shared in common. Study 2 found that existing instruments do not cover the full set of components. Moreover, results indicated that existing scales confound gratitude and gratefulness, and thus they cannot determine the extent to which each construct uniquely relates to wellbeing outcomes.

Conclusions: This work supports the view that gratefulness and gratitude are distinct, yet related, multi-component constructs within a complex system of appreciative functioning. Together, these studies provide theoretical groundwork for the construction of multidimensional measurement instruments to extend research into the underlying mechanisms through which appreciative functioning influences well-being.

Keywords: Appreciative functioning, Gratitude, Gratefulness, Positive psychology, Well-being, Framework, Systems theory 


\section{Background}

Interest in gratitude has grown rapidly over the last two decades (Rusk and Waters 2013), and a growing body of research in the field of positive psychology demonstrates its importance for well-being (Watkins 2014; Wood et al. 2008). However, insufficient attention has been given to how it is defined, understood and measured (Gulliford et al. 2013; Lambert et al. 2009).

The term appreciative functioning will be used to encompasses the two major classes of gratitude definitions in the literature (Lambert et al. 2009), which will be termed gratitude and gratefulness herein. Gratitude will refer to an appraisal of benefit that strictly concerns the agency of another person or entity, while gratefulness will refer to an appraisal of benefit that does not involve the agency of any person or entity.

The current paper approaches appreciative functioning from a complex dynamic systems perspective, which has emerged as a major paradigm to investigate a growing number of psychological processes (Guastello et al. 2008; Vallacher et al. 2010). Dynamic systems involve a set of regularly interacting components, which makes it a particularly suitable paradigm for understanding appreciative functioning, given that several scholars have noted that appreciative functioning is a multifaceted phenomenon (e.g. Chen et al. 2012; Emmons and McCullough 2003). Approaching appreciative functioning as a complex dynamic system allows these multiple facets to be encompassed.

This paper presents two studies that conceptually explore this system of appreciative functioning in greater detail. Study 1 aims to identify and describe the possible psychological and social components that comprise appreciative functioning through a deductive thematic analysis of the relevant literature. The purpose is to develop a multidimensional framework that draws together existing literature, articulates relevant psychological and social mechanisms, and reveals detailed similarities and differences between gratitude and gratefulness. Study 2 aims to extend the analysis from Study 1 in order to determine the extent to which the components discovered in the literature are covered by current measurement scales through a content analysis of their items. The results provide a detailed review of existing scales which may be useful for the development of more holistic, integrated measurement instruments.

\section{Study 1}

A complex systems view of appreciative functioning implies that it involves a plurality of interacting psychological and social processes. However, much of the literature to date has tended to focus on singular processes or constructs. For example, some researchers have focused on the role played by the agency of others in the experience of gratitude (e.g. Watkins et al. 2003). Other scholars have focussed on the importance of directing attention toward good things, through studies of interventions such as Three Good Things (Seligman et al. 2005). Other researchers use specific terms like 'savouring' (e.g. McCullough 2002), 'counter-factual thinking' (e.g. Koo et al. 2008), or 'benefit finding' (e.g. Wood et al. 2007) to describe processes all related to appreciative functioning. Yet other researchers have focused on the relational impact of gratitude expression (e.g. Lambert et al. 2010).

The diversity of these terms and research foci makes the task of integrating and synthesising the research literature difficult. The current study addresses this difficulty by using a common framework to draw together the psychological and social processes 
and constructs that have relevance to appreciative functioning. As such, it represents a much-needed theoretical step toward a more comprehensive view of appreciative functioning.

\section{Methodology}

A deductive thematic analysis (Boyatzis 1998; Braun and Clarke 2006) was used to analyse existing literature and derive a set of components of appreciative functioning. Details of the methodology follow.

\section{Domain Framework}

A guiding theoretical framework is required as the foundation for deductive thematic analyses (Braun and Clarke 2006). For this study, a framework was required that (a) is empirically based, (b) is compatible with a systems approach, and (c) covers the psychological and social aspects that might underpin appreciative functioning. The five-domain framework of Rusk and Waters (2015) met these criteria and was used in the present study. Rusk and Waters empirically derived five domains of positive psychological and social functioning using a cluster analysis of over 3,000 key terms relating to positive psycho-social functioning in approximately 18,000 documents from the field of positive psychology. The source documents covered two decades of research related to positive functioning. The five domains are:

(1) Attention and Awareness, (2) Comprehension and Coping, (3) Emotions, (4) Goals and Habits, and (5) Relationships and Virtues. These five domains formed the theoretical framework within which components of appreciative functioning were identified.

\section{Source Literature}

The literature used for the analysis included a total of 546 scholarly papers, which were identified using a combination of three methods. First, a ProQuest database search was performed to identify scholarly, peer-reviewed papers concerning gratitude, gratefulness and thankfulness written in English from all available years. ${ }^{\text {a }}$ The titles and abstracts were inspected to filter out articles not relevant to the analysis, yielding a total of 301 papers. Second, a backward search methodology was used to identify 161 additional papers related to appreciative functioning that were cited by the papers identified in the search above. Third, taking the view that appreciative functioning involves certain behaviours (e.g. savouring, social expression), a selection of 84 papers from the behavioural literature was also included to enable additional potentially relevant components to be identified. This selection included papers covering Social-Cognitive Theory (Bandura 1977), the Theory of Planned Behaviour (Ajzen 1991), implementation intentions (Gollwitzer and Brandstätter 1997), and habits (Ouellette and Wood 1998).

\section{Analysis}

The analysis focused at the latent level, rather than the semantic level, to identify underlying psychological and social processes and constructs involved in appreciative functioning. Thus, the 'themes' sought in the analysis were not categories of the literature, but instead were categories of psycho-social processes and constructs that the literature identified as relevant to appreciative functioning (e.g. present moment attention, appreciation of simple 
pleasures, gratitude for the agency of others). For clarity, they are referred to herein as "components" rather than "themes". All components had to fit within at least one of the five domains of the theoretical framework.

Components were developed iteratively and reflexively from the literature by the first author to fully, yet parsimoniously, capture relevant psychological and social processes and constructs. As the study was qualitative, not quantitative, no attempt was made to quantify the relative importance of each component, and the prevalence of a given component in the literature was not taken to imply its importance. The research has not yet clarified whether components are causes or consequences of appreciative functioning, or whether reciprocal causative relationships exist. Consequently, the analysis did not attempt to identify only causative components, nor did it attempt to determine whether components are causative or reflective of appreciative functioning. The relevance of each component to gratefulness and gratitude was assessed on the basis of the literature and the definitions of these phenomena used in this paper.

\section{Results}

A total of 32 components were identified through the deductive thematic analysis of the 546 papers. Table 1 shows the 32 components and their assessed relevance to gratefulness and gratitude. Each component of appreciative functioning is defined and outlined in this section with reference to relevant source literature used in the thematic analysis.

\section{The Attention and Awareness Domain}

The first domain of the guiding theoretical framework of the analysis concerns attention and awareness. Several researchers have pointed out that gratefulness necessarily involves awareness, since the benefit must be noticed or recognised (e.g. Adler and Fagley 2005; Wood et al. 2010). Thus, appreciative functioning involves the Attention and Awareness domain, which concerns the consciously controlled or automatic regulation of attention toward particular aspects of sensory or cognitive information (Rusk and Waters 2015). Five components pertaining to appreciative functioning were identified within this domain as follows.

Present moment attention. This component concerns the deliberate directing of attention to the present moment. Benefit appraisals require that a situation of value be attended to and the present moment provides a major source of novel situations of value (Kashdan et al. 2006). Failing to attend to the present moment forgoes a constant stream of opportunities for new benefit appraisals. Present moment attention correlates with gratefulness (e.g. Loo et al. 2014; Adler and Fagley 2005). It is a key ingredient of mindfulness and several researchers have suggested that mindful attentiveness may contribute to appreciative functioning (Fagley and Adler 2012; McCullough 2002). Indeed, Rothaupt and Morgan (2007) found that practising mindfulness can promote appreciative functioning.

Simple pleasures. Simple pleasures in life are common sights or sensations that are often taken for granted, such as sunlight or the sight of leaves in autumn. Dispositionally grateful people are more likely to appreciate simple pleasures (Adler and Fagley 2005; Watkins et al. 2003). Many simple pleasures are commonplace. Hence, if simple 
Table 1 Components of appreciative functioning identified in Study 1

\begin{tabular}{|c|c|}
\hline Component & Description \\
\hline \multicolumn{2}{|l|}{ Attention and Awareness } \\
\hline Present moment & Attending to stimuli in the present moment \\
\hline Simple pleasures & Noticing simple things of value \\
\hline Positive searching & Searching for positive aspects of situations \\
\hline Reminiscence & Attending to positive past situations \\
\hline 'Have' focus & Attending to tangible and intangible assets \\
\hline \multicolumn{2}{|l|}{ Comprehension and Coping } \\
\hline Beliefs of abundance & Belief that one's life has many good things \\
\hline Counter-factual thinking & Considering situations that might have been \\
\hline Social comparison & Comparing one's situation to those of others \\
\hline Impermanence & Appreciating the temporary nature of situations \\
\hline Schemas & Beliefs that influence gratefulness \\
\hline Refocussing & Using gratefulness to combat negative emotions \\
\hline Benefit finding & Finding benefits of negative situations \\
\hline Self-concept & Viewing oneself as a grateful person \\
\hline Self-efficacy & Perceived ability to regulate one's gratefulness \\
\hline \multicolumn{2}{|l|}{ Emotions } \\
\hline Affective gratefulness & The frequency or strength of feeling grateful \\
\hline Contentment & Feeling content with one's life \\
\hline Acceptance & Lacking feelings of resentment or regret \\
\hline Privilege & Feeling privileged or fortunate and not entitled \\
\hline Awe & Feelings of awe and wonder \\
\hline \multicolumn{2}{|l|}{ Goals and Habits } \\
\hline Simplicity & Valuing non-material assets over material goods \\
\hline Valuing gratefulness & Valuing gratefulness as important \\
\hline Intention and motivation & Intending to experience gratefulness \\
\hline Rituals & Having regular habits that promote gratefulness \\
\hline Co-operation & Working together with others to achieve goals \\
\hline Savouring & Rituals enhancing the benefits of positive events \\
\hline \multicolumn{2}{|l|}{ Relationships and Virtues } \\
\hline Agency of others & Benefits provided through the agency of others \\
\hline Costly benefit & Cost to the benefactors of their agency \\
\hline Relational impact & Social consequences of gratitude \\
\hline Social expression & Expressing gratitude to others \\
\hline Kindness & Giving or showing kindness to others \\
\hline Relationships & One's relationships with others \\
\hline Social norms & Social norms that support gratefulness \\
\hline
\end{tabular}

pleasures are attended to, they can present frequent opportunities for gratefulness independently of other circumstances.

Positive searching. Positive searching is a term used to describe a deliberate, effortful attempt to recognise something of perceived value in a given situation. Tucker (2007) has noted the importance of attending to positive aspects of situations for appreciative functioning. Recognising something of perceived value is necessary to make the appraisals of benefit that underlie appreciative functioning (e.g. Adler and Fagley 2005; Wood et al. 2010); hence, positive searching increases the likelihood of making benefit appraisals. 
Positive reminiscence. Deliberately recalling positive memories can be termed positive reminiscence, although Quoidbach, Wood and Hansenne (2009) termed this positive mental time travel. Positive memories provide a potential source of benefit appraisals that is independent of present circumstances, and recalling them can boost happiness (Quoidbach et al. 2009). Reminiscence interventions have been shown to enhance wellbeing and decrease depression (Pinquart and Forstmeier 2012). Interventions such as Three Good Things (Seligman et al. 2005) prompt positive reminiscence by asking participants to list good things that happened during their day, and they have been shown to increase positive emotions. These memory processes are thought to be important in appreciative functioning (Watkins et al. 2009). Using a cross-sectional design with 122 participants, Watkins et al. (2004) found that appreciative functioning is associated with a tendency to recall positive, rather than negative, events.

"Have" focus. This component refers to paying attention to the valuable things that one already has. Adler and Fagley (2005) found that focussing on tangible and intangible assets that one has, as opposed to what one lacks, is a factor of gratefulness. This factor represents a bias toward making comparisons that promote gratefulness (e.g. having versus not having something) and away from comparisons that promote negative emotions.

\section{The Comprehension and Coping Domain}

The second domain in which appreciative functioning was assessed concerns comprehension and coping. Differences exist in how people categorise stimuli, understand causality, and make predictions about the future. Moreover, individuals can also implement a variety of cognitive coping strategies to regulate their emotions during adversity. These cognitive processes can influence the benefit appraisals that underlie appreciative functioning (Watkins 2014) and they relate to the Comprehension and Coping domain (Rusk and Waters 2015). Nine components were identified in this domain, which will now be outlined.

Beliefs of abundance. Beliefs that good things in one's life are abundant, rather than scarce, are termed beliefs of abundance. Watkins et al. (2003) theorised that grateful individuals are more likely to hold such beliefs. People may be more likely to look for benefits when they expect them to be present (a confirmation bias). In support of this idea, Bock et al. (2013) found among US adults that appreciative functioning correlates with beliefs of abundance regarding the U.S. economy, state economy, future job growth, and future income earned. Similarly, Goetz et al. (2006) found that individuals with high well-being overestimate the average well-being of other people in their city.

Counter-factual thinking. Thinking about how one's situation could be or could have been worse is known as counter-factual thinking, and studies have shown that it can prompt gratefulness (Koo et al. 2008; Teigen 1997). Individuals high in appreciative functioning are more likely to engage in counter-factual thinking (Adler and Fagley 2005). Positive counter-factual thinking involves constructing alternative situations against which a person's real situation can be appraised as more valuable, thus prompting gratefulness. For example, Frias et al. (2011) found that contemplation of death, a negative alternative, enhanced gratefulness for life. Counter-factual thinking may allow people to creatively generate benefit appraisals.

Social comparison. Benefit appraisals may also be generated through making downward social comparisons (Wood et al. 2010), in which one's situation is contrasted 
with worse situations experienced by others. An experimental study by Emmons and McCullough (2003) with 157 participants found such downward social comparisons can promote more feelings of gratefulness than writing about daily hassles. Beneficial types of social comparisons have been correlated with appreciative functioning (Adler and Fagley, 2005; Watkins et al. 2003). However, it is not clear whether one can be disposed to social comparisons that produce gratefulness without at the same time being disposed to social comparisons that produce negative emotions such as envy or resentment (Smith 2000). Moreover, engaging in social comparisons can decrease empathy and prosocial behaviour (Yip and Kelly 2013).

Impermanence. Impermanence refers to a temporal perspective of things of value, in which they are seen as temporary and therefore special. Adler and Fagley (2005) identified the importance of not taking benefits for granted in appreciative functioning. Indeed, Frias et al. (2011) showed that reflection on death can enhance appreciative functioning, which may in part be because it provides a reminder of the temporary nature of life and the good things in it. The belief that good things are not permanent may motivate more frequent appraisals of their benefits, and hence gratefulness.

Schemas. Schemas refer to how current knowledge about the world and the self is structured. Wood et al. (2010) suggested that schemas play a role in appreciative functioning. Indeed, appreciative functioning correlates with several self-evaluations, such as "I'm a failure" (negative correlation) and "I'm important" (positive correlation; Toussaint and Friedman 2009). Again due to confirmation bias, such schemas may influence benefit appraisals by biasing the interpretation of situations and the alternatives considered. Such biases may explain why interpretations of the same situation can vary widely. For example, Wood et al. (2008) presented participants with identical vignettes of a hypothetical situation in which they had been helped. Interpretations of motivation, costliness, and value varied widely and explained over $80 \%$ of the variance in reported gratitude. Fagley and Adler (2012) suggested that beliefs of scarcity may also influence appreciative functioning. In relationships, appreciative functioning is influenced by schemas relating to communal relationship (Simão and Seibt 2014), attachment (Mikulincer et al. 2006), and suspicion (Watkins 2014). A reciprocal relationship may also be a possibility, in which schemas are influenced by appreciative functioning. For example, both Emmons and McCullough (2003) and Froh et al. (2008) have found that brief gratefulness exercises can increase participants' optimism about the coming week.

Refocussing. One strategy for combating negative moods is to refocus attention on things to be grateful for. This process generates positive distractions, making it a promising strategy for combating negative rumination and depressive mood (Nolen-Hoeksema et al. 2008; Watkins 2014). Coping styles correlate with appreciative functioning (Wood et al. 2007), with individuals high in appreciative functioning tending to have active, emotion-focused strategies for dealing with negative emotions and stress (Lin and Yeh 2014).

Benefit finding. Benefit finding involves the consideration of benefits that have arisen from adverse situations. This process has also been called positive reinterpretation (Lambert et al. 2009) and positive reframing (Lambert et al. 2012). Research has linked benefit finding with appreciative functioning (e.g. Watkins et al. 2008; Wood et al. 2007). Moreover, benefit finding and appreciative functioning more broadly have been 
correlated with successful adaptation to traumatic life events, such as spinal cord injury (Chun and Lee 2012). Ruini and Vescovelli (2013) found among breast cancer patients that appreciative functioning correlated with reduced distress and more positive emotion. Individuals high in appreciative functioning are less likely to exhibit posttraumatic stress (Lies et al. 2014) and Tedeschi and Calhoun (1996) found that 'appreciation of life' is a factor in posttraumatic growth.

Grateful self-concept. One's self-assessed level of appreciative functioning is termed grateful self-concept. Individuals high in appreciative functioning are more likely to have higher grateful self-concept and report that adjectives like 'grateful', 'thankful', and 'appreciative' describe them accurately (Froh et al. 2011b). Participants in a study aimed at cultivating appreciative functioning by Proyer et al. (2013) subsequently reported higher grateful self-concept at post-test. Grateful self-concept may also promote appreciative functioning. For example, it may lead to a 'self-fulfilling prophecy', whereby people who already see themselves as highly appreciative may be motivated to act in ways congruent with that view by thanking others.

Grateful self-efficacy. Self-efficacy is the degree to which individuals feel capable of performing a particular behaviour (Bandura 1977). Grateful self-efficacy is the degree to which individuals believe they can feel grateful if they were to attempt to do so. Individuals who feel confident they can enact a particular behaviour are more likely to attempt the behaviour (Armitage and Conner 2001), and this principle may be true of appreciative functioning. Indeed, concepts involved in appreciative functioning have been correlated with general self-efficacy (Rey 2009) and enhancing or limiting self-beliefs (Toussaint and Friedman 2009). Individuals may be more likely to engage effortful attentional and cognitive processes to cultivate gratefulness if they believe such efforts will be effective. Successfully cultivating feelings of gratefulness may, in turn, build gratefulness self-efficacy beliefs (Bandura 1977).

\section{The Emotions Domain}

The third domain in the analysis framework is the Emotions domain, which Rusk and Waters (2015) conceptualise as involving present-moment experiences of emotion as well as emotional associations with stimuli and memories. Emotional experience has been the focus of much psychological research on appreciative functioning and several varieties of emotions or emotionally valenced cognitions associated with appreciative functioning can be distinguished. Five components were identified in this domain, which will be outlined below.

Affective gratefulness. The emotional experience associated with episodes of gratefulness is termed affective gratefulness here. Such emotions are highly correlated with components of appreciative functioning (Adler and Fagley 2005; Watkins et al. 2003). Positive emotions like affective gratefulness have been shown to influence functioning in the Attention and Awareness and Comprehension and Coping domains (Fredrickson 2004). Consequently, some have suggested that affective gratefulness may form reciprocally supportive interactions that result in 'upward spirals' (e.g. Lambert et al. 2009; Lyubomirsky and Layous 2013).

Contentment. Finding and comprehending more benefits in one's life is likely to enhance feelings of contentment or satisfaction with life, and appreciative functioning has been shown to correlate with life satisfaction (Fagley 2012; Wood et al. 2008). Lambert et al. (2009) showed that experimentally induced appreciative functioning can lead 
to a response of higher life satisfaction, in contrast with experimentally induced envy. In a cross-sectional design, Froh et al. (2011) found that appreciative functioning was negatively correlated with envy. Hence, it may be that appreciative functioning both promotes contentment and counteracts opposing emotions such as envy. Consistent with this idea, appreciative functioning has been shown to correlate negatively with negative affect (e.g. Watkins et al. 2003).

Acceptance and forgiveness. Watkins et al's (2003) scale included several items that ostensibly measure regret and resentment about past situations, which are conceptually opposed to acceptance and forgiveness, respectively. Wood et al. (2009) found that appreciative functioning is strongly correlated with self-acceptance $(\mathrm{r}=0.61, \mathrm{p}<0.001)$. Forgiveness has also been widely studied in relation to appreciative functioning and the two are theoretically linked constructs (Breen et al. 2010). Dispositional appreciative functioning correlates with the tendency to forgive (e.g. Breen et al. 2010; Neto 2007). Benefit-finding, a specific component of appreciative functioning, also facilitates forgiveness of an interpersonal transgression (McCullough et al. 2006).

Privilege. Feeling privileged or fortunate is positively correlated with appreciative functioning (Watkins et al. 2003). Such feelings are consistent with a tendency to compare one's situations against worse alternatives. At the other end of the spectrum, appreciative functioning is negatively associated with a sense of entitlement (Exline 2012). If a situation is compared against a more valued alternative that one feels entitled to or deserving of, the resulting appraisal will not be one of benefit, but of deficit. Rather than prompting affective gratefulness, deficit appraisals are likely to prompt emotions relating to deprivation or unfairness. Feelings of deprivation or unfairness correlate negatively with appreciative functioning (Watkins et al. 2003).

Feelings of awe. According to Haidt and Keltner (2003), awe is an emotion arising from positive stimuli that are perceived as much larger than the self and difficult to fully comprehend. While affective gratefulness often results from reflecting on a situation, awe tends to involve experiential absorption (Bryant and Veroff 2007). Adler and Fagley (2005) showed that feelings of awe correlate with appreciative functioning and suggested that awe can be a direct affective manifestation of appreciation. Awe shares many of the attentional and comprehension processes of appreciative functioning and can be experienced for particularly potent benefit appraisals.

\section{The Goals and Habits Domain}

Six components relating to appreciative functioning were identified in the fourth domain of the analysis framework, which concerns one's goals and habits. Components in this domain focus on enduring values, rules, principles, and goals involved in guiding behaviour, as well as the habits and skills involved in the execution of those behaviours (Rusk and Waters 2015).

Simplicity. Polak and McCullough (2006) and Diessner and Lewis (2007) have shown that appreciative functioning is negatively correlated with materialism. Framed positively, appreciative functioning correlates with what can be termed simplicity, defined as a tendency to value non-material assets over material ones. Gordon et al. (2012) have suggested that appreciative functioning may serve to re-prioritise peoples' goals, and Froh et al. (2011a) have argued that appreciative functioning influences goal pursuit. 
Simplicity-oriented goals may, in turn, influence appreciative functioning by increasing the likelihood that non-material benefits will be considered, independently of what material assets one has. Hence, Watkins (2014) has suggested that simplicity and appreciative functioning may support each other.

Valuing gratefulness. The degree to which individuals report that they value gratefulness correlates with measures of appreciative functioning (Adler and Fagley 2005; Watkins et al. 2003). Individuals who highly value it are presumably more motivated to engage in attentional and cognitive practices that promote gratitude. In a study by Seligman et al. (2005), several participants assigned to the "Three Good Things" intervention for several weeks decided to continue to practice the exercise after the intervention had ended, presumably because they found it valuable. Their continued practice correlated with higher levels of well-being. This study provides evidence that a change in the degree to which one values appreciative functioning and activities designed to cultivate it can influence the degree to which it is experienced.

Intention and motivation. Intentions are planned choices concerning future behaviours and reflect an individual's motivation to perform those behaviours (Ajzen 1991). Findings of Sheldon and Lyubomirsky (2006) demonstrate the importance of self-concordant motivation for appreciative functioning. In their study, participants' motivation significantly influenced the actual practice of an appreciative functioning exercise. Intention has been shown to be a predictor of future behaviour (Webb and Sheeran 2006), particularly when it is accompanied by implementation intentions, which are specific plans to engage in particular behaviours in specific situations (Gollwitzer and Brandstätter 1997). Hence, appreciative functioning may be more likely when one intends and plans to cultivate it in specific ways.

Rituals. Behaviours that are routinely practised in constant contexts can become rituals (or habits) because the processing that initiates and controls their performance becomes automatic (Ouellette and Wood 1998). Adler and Fagley (2005) found that certain rituals, such as expressing thanks when beginning a meal, correlate with appreciative functioning. Rituals such as gratitude journaling before going to sleep help to cultivate gratefulness (Seligman et al. 2005). These rituals may be important for understanding the formation of grateful dispositions.

Co-operation. Gratitude involves an appreciation of what other people have done on one's behalf. Individuals who routinely co-operate in a team environment with other people have increased opportunity to receive regular help than those who tend to work more independently. In keeping with this idea, Chen (2013) found that the perceived support provided from coaches and team-mates mediated the gratefulness of adolescent athletes. However, this component is nuanced, since co-operation also increases the possibility of being taken advantage of; hence, it could also foster resentment.

Savouring. Savouring is a broad term related to a set of actions taken to generate, prolong, or intensify the emotional benefits from positive events that happen (Bryant 1989; Hurley and Kwon 2013). According to McCullough (2002), savouring makes episodes of appreciative functioning more likely. Methods of savouring include celebrating positive events and mentally replaying them later on (Quoidbach et al. 2010). Bryant and Veroff (2007) suggested that appreciative functioning can be cultivated by a savouring habit of 'thanksgiving', in which one deliberately reflects on things to be thankful for. 


\section{The Relationships and Virtues Domain}

Seven components were identified in the fifth and final domain in the analysis framework: Relationships and Virtues. This domain concerns enduring social relationships, momentary social interactions, and the individual virtues and behaviour that influence their quality (Rusk and Waters 2015). Gratitude is inherently social in nature because it relies on the actions of other people. Hence, gratitude in particular relates to the Relationships and Virtues domain. This section will outline the seven components in this domain and how they relate to appreciative functioning.

Agency of others. This component relates to actions benefactors take on behalf of the individual. At the heart of gratitude is a benefit appraisal of the agency of another (Watkins 2014). Gratitude is felt when a benefit is perceived as being due to the agency of another (Bono and McCullough 2006; Tsang et al. 2008; Watkins 2014), but not when it is perceived as due to one's own agency (Emmons and Crumpler 2000). This component represents a major aspect of how gratitude has been measured to date (McCullough et al. 2002; Watkins et al. 2003).

Cost to benefactor. Benevolent actions frequently incur some cost to the benefactor. Several scholars have argued that gratitude is experienced more strongly when the benefactor has incurred some personal cost to benefit the recipient (e.g. Gulliford et al. 2013). It may be that dispositionally grateful individuals are more likely to perceive benevolent agency as costly.

Social expression. Thanking other people through words or actions concerns the social expression of gratitude. Expressing gratitude motivates benefactors to engage in further prosocial behaviour (Grant and Gino 2010), increasing the likelihood of future benevolence and, hence, future gratitude by the recipient. Expressing gratitude enhances the perceived communal strength of relationships (Lambert et al. 2010) and enhances marital satisfaction (Gordon et al. 2011). Emotional expression may also play a role in moderating the effects of gratitude on one's own well-being (Chen et al. 2012).

Relational impact. Individuals may be more likely to notice and be thankful for what others do for them when there are important social consequences of doing so; that is, when there is significant relational impact associated with gratitude. Evidence suggests gratitude impacts relationships in a range of ways. For example, Lambert et al. (2010) found that expressing gratitude to a relationship partner enhances the expresser's perception of the communal strength of the relationship. A study by Lambert and Fincham (2011) showed that expressing gratitude also leads to more relationship maintenance behaviour. In two studies, Bartlett et al. (2012) found evidence that gratitude can promote social affiliation and socially inclusive behaviours. Individuals may be more likely to express gratitude when they perceive these relational benefits are more likely or more important.

Kindness. Lambert et al. (2009) found the terms 'kindness', 'giving', and 'being caring' are an integral part of lay-person's conception of gratitude. Kindness may not only be a cause for gratitude, though, since gratitude may prompt acts of kindness. Weiner and Graham (1989) saw gratitude as "a stimulus to return a favor" (p. 403) and it has been shown to motivate people to help others (e.g. Bartlett and DeSteno 2006; Tsang 2006). Gratitude is positively correlated with altruism (Wood et al. 2009).

Relationships. One's established relationships provide another potential source of benefit appraisals to promote gratefulness. Indeed, Gordon et al. (2004) found that family 
members were the most common source of gratefulness among both male and female children. Adler and Fagley (2005) found that one factor of gratefulness relates to an appreciation of people and interpersonal relationships themselves, rather than of specific benefits from others.

Supportive social norms. This component concerns social norms that support appreciative functioning. According to many common models of behaviour, supportive social norms for a behaviour increase the likelihood that individuals will engage in it (e.g. Albarracín et al. 2004). Participation in groups where appreciative functioning is common thus increases the likelihood of appreciative functioning for the individual. Groups in which appreciative functioning is normative can also cultivate appreciative functioning more directly. Expressions of gratefulness can promote benevolence within a whole social group, which increases the likelihood that an individual will have opportunity for gratitude (Chang et al. 2012). Froh et al. (2010) also found that gratitude and social integration serially enhance each other among adolescents.

\section{Discussion}

Within a complex systems approach, appreciative functioning can be conceptualised not as a single construct, but rather as a pattern of cognition and behaviour that involves the interaction of awareness, comprehension, emotions, goals, and relationships. Analysis of the literature identified 32 components that fall under the five domains of positive functioning. They are proposed as a multidimensional framework of components that comprise appreciative functioning. The 32 components articulate the relevant psychological and social processes involved in both gratefulness and gratitude. The next study will examine the degree to which these 32 components derived from the literature in Study 1 are also present in existing scales that measure gratefulness and/or gratitude.

\section{Study 2}

The first study investigated appreciative functioning as a system of interacting components that relate to the experiences of gratitude and gratefulness. The deductive thematic analysis of 546 papers identified 32 psychological and social components of appreciative functioning. However, empirical research requires empirically validated measurement instruments. With this need in mind, Study 2 aims to quantify the extent to which existing validated measurement scales cover each of the 32 components of appreciative functioning.

\section{Selection of existing scales}

Relevant English-language instruments were identified from the 462 papers relating to appreciative functioning sourced in Study 1 (the 84 papers from behavioural literature were excluded). Five instruments were identified for inclusion in the analysis, which are shown in Table 2. The Appreciation in Relationships scale developed by Gordon et al. (2012) was excluded because of its narrow focus on gratitude within a romantic relationship. These instruments are outlined briefly below.

\section{GQ-6}

The Gratefulness Questionnaire (GQ-6) was an early unifactorial measure of gratitude devised by McCullough et al. (2002) for an intervention study. It consists of six statements 
designed to measure the intensity, frequency, density, and span of gratitude (see Froh et al. 2011b), but it does not provide a detailed view of the different aspects of appreciative functioning.

\section{GRAT-R}

The Gratitude, Resentment and Appreciation Test (GRAT-R) developed by Watkins et al. (2003) and revised by Thomas and Watkins (2003) consists of 44 items. Exploratory factor analysis of the original scale found three factors. The first factor, 'simple appreciation, concerned the appreciation of simple, present moment stimuli. A second factor concerned the appreciation of others, particularly for their benevolent agency. The final factor concerned resentment and beliefs of abundance, such as feelings of unfair deprivation or beliefs that good things are plentiful in life.

Al

The Appreciation Inventory (AI) developed by Adler and Fagley (2005) consists of 57 items that assess the frequency of events concerning appreciation and attitudes related to it. Exploratory factor analysis revealed several factors: a "have" focus; feelings of awe; rituals associated with appreciation; appreciation of things in the present moment; self and social comparison; general gratefulness; dealing with loss or adversity; and interpersonal appreciation.

\section{VIA-IS Gratitude Subscale}

The 240-item Values in Action Inventory of Strengths (VIA-IS) of Peterson et al. (2005) contains a 10-item subscale designed to measure dispositional gratitude. The items relate to feelings of thankfulness, appreciation, and blessing; expressing thankfulness to others; routines of gratefulness; finding things to feel grateful for; and responding with strong emotions to stories of generosity.

\section{GAC}

The Gratitude Adjective Checklist (GAC) of McCullough et al. (2002) comprises only three adjectives: 'grateful', 'thankful', and 'appreciative'. Respondents rate the degree to which these adjectives accurately describe them.

\section{Methodology}

A content analysis methodology (Krippendorff 2013) was used to quantify the theoretical content coverage of the existing scales. Items within the scales were used as the unit of analysis, and all scale items were assessed. The 32 components identified in Study 1 were used as the analytical constructs for Study 2 . All 32 components were sequentially considered with respect to each item in each scale. An item was deemed relevant to a component if the process(es) or construct(s) addressed by the item at face value overlapped conceptually with those of the component.

Coding was performed by each of the three authors. Relevance was coded using one of three levels. The 'strong' level was used in cases where there was large conceptual overlap between the component and the item. The 'medium' level was used where there was moderate conceptual overlap, and the 'weak' level was used where there was only small 
conceptual overlap. Where none of the previous three levels could be met, no entry was made, which indicated that the component was not relevant to the item. Inter-rater reliability was assessed using a two-way mixed, consistency, intra-class correlation (ICC, McGraw and Wong 1996). The final relevance of each item to each component was taken as median relevance given by the three coders.

\section{Results}

Results of Study 2 are summarised in Table 2. This table shows the number of items in each scale that relate to each component of appreciative functioning identified in Study 1. Ranges reflect the uncertainty associated with the 'weak' category, with the lower numbers including relationships in only the strong and medium categories and the higher numbers including relationships in all strength categories. Within each scale, components to which five or more items relate are shown in italics. Inter-rater reliability was strong (ICC $=0.92$ with a 95\% confidence interval of 0.91-0.93; Cicchetti 1994), indicating that coders provided consistency in their ratings of relevance across all items-component combinations.

Table 2 reveals which components are shared between scales or unique foci of particular scales. Two or more scales have items that relate to present moment attention, simple pleasures, affective gratefulness, privilege, and agency of others. Unique focal components of the GRAT-R include schemas, acceptance, valuing gratefulness, co-operation, and social comparison. The AI encompasses a larger number of unique foci: positive searching, "have" focus, counter-factual thinking, impermanence, benefit finding, intention and motivation, rituals, costly benefit, social expression, and relationships. Lastly, gratefulness self-concept is a unique focus of the GAC.

Summary statistics of component coverage for each scale are given in Table 3 . The GAC and the GQ- 6 contain three and six items, respectively, and so they cover relatively few components. The 10-item subscale of the VIA-IS covers 9-13 components. The large scales, the GRAT-R and the AI, cover as many as 23 components. In the GRAT-R, 4-10 components are covered by five or more items, while the AI covers 9-15 components with five or more items. Hence, the AI is the most theoretically comprehensive instrument to measure appreciative functioning to date. However, it must be noted that there is no existing scale that measures all 32 components of appreciative functioning.

\section{Discussion}

Items in the existing scales relate to a range of components across all five domains of psycho-social functioning described earlier. This result is pertinent to the development of integrated scales to measure appreciative functioning in detail. It suggests that such scales would cover all five domains, rather than focussing on only a small number of domains. Yet, currently, no scale measures all 32 components.

The degree to which existing scales relate to both gratitude and gratefulness deserves attention. Table 2 shows the hypothesised relevance of the 32 components to gratitude and gratefulness. Many of the focal components of the existing scales relate to gratitude. However, there are notable exceptions that relate much more to gratefulness than to gratitude, most notably: simple pleasures, "have" focus, impermanence, and acceptance. Hence, existing scales contain some components that relate to gratitude and others that relate to gratefulness. However, these scales have not explicitly separated gratitude 
Table 2 Component coverage of existing scales as determined in Study 2

\begin{tabular}{|c|c|c|c|c|c|c|c|}
\hline \multirow[t]{2}{*}{ Component } & \multicolumn{5}{|l|}{ Scale } & \multicolumn{2}{|c|}{ Type of AF } \\
\hline & GQ-6 & GRAT-R & Al & VIA & GAC & GF & GT \\
\hline \multicolumn{8}{|l|}{ Attention and Awareness } \\
\hline Present moment & - & $1-5$ & $3-7$ & $0-1$ & - & $\checkmark$ & $\checkmark$ \\
\hline Simple pleasures & - & $13-14$ & $9-11$ & - & - & $\checkmark$ & - \\
\hline Positive searching & 1 & 1 & $5-6$ & 2 & - & $\checkmark$ & $\checkmark$ \\
\hline Reminiscence & 1 & - & - & - & - & $\checkmark$ & $\checkmark$ \\
\hline 'Have' focus & 1 & $3-4$ & $11-16$ & $1-2$ & - & $\checkmark$ & - \\
\hline \multicolumn{8}{|l|}{ Comprehension and Coping } \\
\hline Beliefs of abundance & $2-3$ & $2-3$ & $0-1$ & 2 & - & $\checkmark$ & $?$ \\
\hline Counter-factual thinking & - & - & $4-6$ & - & - & $\checkmark$ & $\checkmark$ \\
\hline Social comparison & - & $4-8$ & 3 & - & - & $\checkmark$ & - \\
\hline Impermanence & - & 1 & $6-7$ & - & - & $\checkmark$ & - \\
\hline Schemas & $0-2$ & $4-5$ & - & $0-1$ & - & $\checkmark$ & $?$ \\
\hline Refocussing & - & - & 2 & - & - & $\checkmark$ & - \\
\hline Benefit finding & - & - & $2-6$ & - & - & $\checkmark$ & - \\
\hline Self-concept & - & - & - & 1 & 3 & $\checkmark$ & $\checkmark$ \\
\hline Self-efficacy & - & - & - & - & - & $\checkmark$ & $?$ \\
\hline \multicolumn{8}{|l|}{ Emotions } \\
\hline Affective gratefulness & $2-5$ & $3-10$ & $0-7$ & 3 & - & $\checkmark$ & $\checkmark$ \\
\hline Contentment & - & - & $2-3$ & - & - & $\checkmark$ & - \\
\hline Acceptance & - & $0-7$ & - & - & - & $\checkmark$ & $?$ \\
\hline Privilege & - & $10-11$ & $8-10$ & 1 & - & $\checkmark$ & $\checkmark$ \\
\hline Awe & - & 3 & $2-3$ & $0-1$ & - & $\checkmark$ & $?$ \\
\hline \multicolumn{8}{|l|}{ Goals and Habits } \\
\hline Simplicity & - & $2-3$ & $0-3$ & - & - & $\checkmark$ & - \\
\hline Valuing gratefulness & - & 5 & $2-3$ & - & - & $\checkmark$ & $\checkmark$ \\
\hline Intention and motivation & - & 1 & $1-6$ & 2 & - & $\checkmark$ & $\checkmark$ \\
\hline Rituals & - & $1-2$ & $8-9$ & $3-4$ & - & $\checkmark$ & $\checkmark$ \\
\hline Co-operation & - & $2-6$ & - & - & - & - & $\checkmark$ \\
\hline Savouring & - & $1-2$ & 2 & - & - & $\checkmark$ & - \\
\hline \multicolumn{8}{|l|}{ Relationships and Virtues } \\
\hline Agency of others & 2 & $8-9$ & $5-6$ & - & - & - & $\checkmark$ \\
\hline Costly benefit & - & - & $4-5$ & - & - & - & $\checkmark$ \\
\hline Relational impact & - & - & - & - & - & - & $\checkmark$ \\
\hline Social expression & $0-2$ & $0-1$ & $7-8$ & 3 & - & $?$ & $\checkmark$ \\
\hline Kindness & - & - & - & - & - & $?$ & $\checkmark$ \\
\hline Relationships & $0-3$ & 2 & 6 & $0-1$ & - & $?$ & $\checkmark$ \\
\hline Social norms & - & - & - & - & - & $\checkmark$ & $\checkmark$ \\
\hline
\end{tabular}

Numbers indicate how many items in each scale are relevant to each component, with italic typeface used where five or more items are relevant. $\mathrm{AF}=$ appreciative functioning; $\mathrm{GF}=$ gratefulness; $\mathrm{GT}=$ gratitude. Existing measurement scales: GQ-6 = Gratefulness Questionnaire (McCullough et al. 2002); GRAT-R = Gratitude, Resentment and Appreciation Test (Thomas and Watkins 2003; Watkins et al. 2003); AI = Appreciation Inventory (Adler and Fagley 2005); VIA = gratitude subscale of the Values in Action Inventory of Strengths (Peterson et al. 2005); GAC = Gratitude Adjective Checklist (McCullough et al. 2002).

from gratefulness in their scoring. By doing so, these scales confound gratefulness with gratitude, making it impossible to determine the extent to which each relates uniquely to well-being outcomes.

The large number of components at play in gratefulness and gratitude is consistent with a systems-based understanding of appreciative functioning. It can be seen that 
Table 3 Summary statistics of component coverage of existing scales

\begin{tabular}{llllll}
\hline Scale statistic & GQ-6 & GRAT-R & Al & VIA & GAC \\
\hline Sum of coverage over all components $^{\mathrm{a}}$ & $9-20$ & $67-103$ & $92-136$ & $18-24$ & 3 \\
Number of components covered by 1 or more items $^{-6}$ & 6 & $19-21$ & $20-23$ & $9-13$ & 1 \\
Number of components covered by 5 or more items & $0-1$ & $4-10$ & $9-15$ & 0 & 0 \\
Number of items in the scale & 6 & 44 & 57 & 10 & 3
\end{tabular}

Abbreviations correspond with those in Table 2.

a Some items covered more than one component.

no one component adequately represents gratefulness or gratitude. Rather, appreciative functioning appears likely to involve many components operating together to create overall patterns of behaviour of the appreciative functioning system. Gratitude and gratefulness share many components in three of the domains (Attention and Awareness, Emotions, and Goals and Habits), reinforcing the importance of including both within a system of appreciative functioning. However, components in the Relationships and Virtues domain relate mainly to gratitude, while components in the Comprehension and Coping domain relate primarily to gratefulness.

\section{General Discussion and Conclusions}

This paper has argued for a systems-based approach to gratefulness and gratitude that comprises five domains of positive psycho-social functioning. The five domains were used in Study 1 to analyse the relevant literature and identify 32 unique components of appreciative functioning. These components were then mapped against existing measurement instruments using content analysis in Study 2. The results of these two studies have several implications for how gratefulness and gratitude can be understood and researched more effectively.

The 32 components of appreciative functioning provide a detailed insight into individual processes and influences involved in gratitude and gratefulness. Several components of appreciative functioning are present within each of the five domains of psycho-social functioning outlined by Rusk and Waters (2015), supporting the view that appreciative functioning can be understood as a multidimensional system.

It must be noted that conceptual overlap exists between some of the components. For example, present moment attention may involve the appreciation of simple pleasures, and finding benefits from adversity may involve a degree of positive searching. Such overlap is to be expected if, indeed, the multiple components operate collectively as a system. It is hoped that this framework will guide future research into both the unique effects of the components and the shared variance (i.e. overlap) of the components.

The results of both studies herein can be used to assist the design of intervention studies to explore the mechanisms involved in appreciative functioning. For example, interventions designed to cultivate a specific component may influence a range of other components, and this mechanism could be quantified. As another example, interventions designed to cultivate not one, but multiple, components could be tested to determine whether broader, systems-based interventions are more effective. This framework provides a platform for the development of a new scale of appreciative functioning, given that many aspects of appreciative functioning outlined in the literature are not measured adequately in the existing scales. To move research forward, a comprehensive multi-component scale that assesses appreciative functioning across all five domains of 
positive functioning is needed. This scale would answer the call by Wood et al. (2008) for a new scale that integrates the existing instruments. Moreover, such a scale could address the current confusion between gratefulness and gratitude by incorporating items designed to measure these two aspects more independently. Factor analysis could then test the independence of these two aspects and identify a parsimonious factor structure for the 32 components.

\section{Conclusion}

In summary, the framework and analysis presented herein steps toward a multidimensional view of appreciative functioning as a psycho-social system. Two varieties of appreciative functioning, gratefulness and gratitude, span five domains of psycho-social functioning and are operationalised by 32 different components. Some components are shared by both gratitude and gratefulness (e.g. rituals), while others components pertain to only one (e.g. agency of others). This framework offers a means to conceptualise appreciative functioning with more clarity and develop refined measurement scales to explore its relationship with well-being. In light of the growing evidence that appreciative functioning is, indeed, important for well-being (Watkins 2014; Wood et al. 2008), more research is needed to explore the role of each of the psychological and social components outlined herein.

\section{Endnotes}

aThe search string was: "(IF(gratitude OR gratefulness OR thankfulness) OR SU(gratitude OR grateful-ness OR thankfulness)) AND PEER(yes) AND SCHOL(yes) AND LA(English) ".

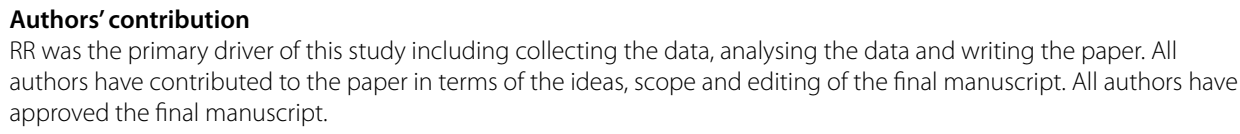

Compliance with ethical guidelines

Competing interests

The authors declare that they have no competing interests.

Received: 10 December 2014 Accepted: 4 June 2015

Published online: 04 July 2015

\section{References}

Adler, M. G., \& Fagley, N. S. (2005). Appreciation: Individual differences in finding value and meaning as a unique predictor of subjective well-being. Journal of Personality, 73(1), 79-114. doi:10.1111/j.1467-6494.2004.00305.x.

Ajzen, I. (1991). The theory of planned behavior. Organizational Behavior and Human Decision Processes, 50(2), $179-211$. doi:10.1016/0749-5978(91)90020-T.

Albarracín, D., Kumkale, G. T., \& Johnson, B. T. (2004). Influences of social power and normative support on condom use decisions: A research synthesis. AIDS Care, 16(6), 700-723. doi:10.1080/09540120412331269558.

Armitage, C. J., \& Conner, M. (2001). Efficacy of the theory of planned behaviour: A meta-analytic review. British Journal of Social Psychology, 40(4), 471-499. doi:10.1348/014466601164939.

Bandura, A. (1977). Self-efficacy: Toward a unifying theory of behavioral change. Psychological Review, 84(2), $191-215$. doi:10.1037/0033-295X.84.2.191.

Bartlett, M. Y., Condon, P., Cruz, J., Baumann, J., \& Desteno, D. (2012). Gratitude: Prompting behaviours that build relationships. Cognition and Emotion, 26(1), 2-13. doi:10.1080/02699931.2011.561297.

Bartlett, M. Y., \& DeSteno, D. (2006). Gratitude and prosocial behavior: Helping when it costs you. Psychological Science, 17(4), 319-325. doi:10.1111/j.1467-9280.2006.01705.x.

Bock, D. E., Eastman, J. K., \& McKay, B. P. (2013). Exploring the relationship between gratitude and economic perceptions. Journal of Business and Economics Research, 11(11), 445-454.

Bono, G., \& McCullough, M. E. (2006). Positive responses to benefit and harm: Bringing forgiveness and gratitude into cognitive psychotherapy. Journal of Cognitive Psychotherapy, 20(2), 147-158. doi:10.1891/088983906780639835. 
Boyatzis, R. E. (1998). Transforming qualitative information: Thematic analysis and code development. Thousand Oaks: SAGE Publications Inc.

Braun, V., \& Clarke, V. (2006). Using thematic analysis in psychology. Qualitative Research in Psychology, 3(2), 77-101. doi:10 $.1191 / 1478088706$ qp063oa.

Breen, W. E., Kashdan, T. B., Lenser, M. L., \& Fincham, F. D. (2010). Gratitude and forgiveness: Convergence and divergence on self-report and informant ratings. Personality and Individual Differences, 49(8), 932-937. doi:10.1016/j. paid.2010.07.033.

Bryant, F. B. (1989). A four-factor model of perceived control: Avoiding, coping, obtaining, and savoring. Journal of Personality, 57(4), 773-797. doi:10.1111/j.1467-6494.1989.tb00494.x.

Bryant, F. B., \&Veroff, J. (2007). Savoring: A new model of positive experience. Mahwah: Lawrence Erlbaum Associates Publishers.

Chang, Y.-P., Lin, Y.-C., \& Chen, L. H. (2012). Pay it forward: Gratitude in social networks. Journal of Happiness Studies, 13(5), 761-781. doi:10.1007/s10902-011-9289-z

Chen, L. H. (2013). Gratitude and adolescent athletes' well-being: The multiple mediating roles of perceived social support from coaches and teammates. Social Indicators Research, 114(2), 273-285. doi:10.1007/s11205-012-0145-2.

Chen, L. H., Chen, M.-Y., \& Tsai, Y.-M. (2012). Does gratitude always work? Ambivalence over emotional expression inhibits the beneficial effect of gratitude on well-being. International Journal of Psychology, 47(5), 381-392. doi:10.1080/0020 7594.2011.632009

Chun, S., \& Lee, Y. (2012). "I am just thankful”: The experience of gratitude following traumatic spinal cord injury. Disability and Rehabilitation, 35(1), 11-19. doi:10.3109/09638288.2012.687026.

Cicchetti, D. V. (1994). Guidelines, criteria, and rules of thumb for evaluating normed and standardized assessment instruments in psychology. Psychological Assessment, 6(4), 284-290. doi:10.1037/1040-3590.6.4.284.

Diessner, R., \& Lewis, G. (2007). Further validation of the Gratitude, Resentment, and Appreciation Test (GRAT). The Journal of Social Psychology, 147(4), 445-447. doi:10.3200/SOCP.147.4.445-448.

Emmons, R. A., \& Crumpler, C. A. (2000). Gratitude as a human strength: Appraising the evidence. Journal of Social and Clinical Psychology, 19(1), 56-69. doi:10.1521/jscp.2000.19.1.56.

Emmons, R. A., \& McCullough, M. E. (2003). Counting blessings versus burdens: An experimental investigation of gratitude and subjective well-being in daily life. Journal of Personality and Social Psychology, 84(2), 377-389. doi:10.1037/0022-3514.84.2.377.

Exline, J. J. (2012). Humility and the ability to receive from others. Journal of Psychology and Christianity, 31(1), 40-50.

Fagley, N. S. (2012). Appreciation uniquely predicts life satisfaction above demographics, the Big 5 personality factors, and gratitude. Personality and Individual Differences, 53(1), 59-63. doi:10.1016/j.paid.2012.02.019.

Fagley, N. S., \& Adler, M. G. (2012). Appreciation: A spiritual path to finding value and meaning in the workplace. Journal of Management, Spirituality and Religion, 9(2), 167-187. doi:10.1080/14766086.2012.688621.

Fredrickson, B. L. (2004). Gratitude, like other positive emotions, broadens and builds. The psychology of gratitude (pp. 145-166). New York: Oxford University Press.

Frias, A., Watkins, P. C., Webber, A. C., \& Froh, J. J. (2011). Death and gratitude: Death reflection enhances gratitude. The Journal of Positive Psychology, 6(2), 154-162. doi:10.1080/17439760.2011.558848.

Froh, J. J., Bono, G., \& Emmons, R. A. (2010). Being grateful is beyond good manners: Gratitude and motivation to contribute to society among early adolescents. Motivation and Emotion, 34(2), 144-157. doi:10.1007/s11031-010-9163-z.

Froh, J. J., Emmons, R. A., Card, N. A., Bono, G., \& Wilson, J. A. (2011a). Gratitude and the reduced costs of materialism in adolescents. Journal of Happiness Studies, 12(2), 289-302. doi:10.1007/s10902-010-9195-9.

Froh, J. J., Fan, J., Emmons, R. A., Bono, G., Huebner, E. S., \& Watkins, P. (2011b). Measuring gratitude in youth: Assessing the psychometric properties of adult gratitude scales in children and adolescents. Psychological Assessment, 23(2), 311-324. doi:10.1037/a0021590.

Froh, J. J., Sefick, W. J., \& Emmons, R. A. (2008). Counting blessings in early adolescents: An experimental study of gratitude and subjective well-being. Journal of School Psychology, 46(2), 213-233. doi:10.1016/j.jsp.2007.03.005.

Goetz, T., Ehret, C., Jullien, S., \& Hall, N. C. (2006). Is the grass always greener on the other side? Social comparisons of subjective well-being. The Journal of Positive Psychology, 1(4), 173-186. doi:10.1080/17439760600885655.

Gollwitzer, P., \& Brandstätter, V. (1997). Implementation intentions and effective goal pursuit. Journal of Personality and Social Psychology, 73(1), 186-199. doi:10.1037/0022-3514.73.1.186.

Gordon, C. L., Arnette, R. A. M., \& Smith, R. E. (2011). Have you thanked your spouse today? Felt and expressed gratitude among married couples. Personality and Individual Differences, 50(3), 339-343. doi:10.1016/j.paid.2010.10.012.

Gordon, A. M., Impett, E. A., Kogan, A., Oveis, C., \& Keltner, D. (2012). To have and to hold: Gratitude promotes relationship maintenance in intimate bonds. Journal of Personality and Social Psychology, 103(2), 257-274. doi:10.1037/a0028723.

Gordon, A. K., Musher-Eizenman, D. R., Holub, S. C., \& Dalrymple, J. (2004). What are children thankful for? An archival analysis of gratitude before and after the attacks of September 11. Journal of Applied Developmental Psychology, 25(5), 541-553. doi:10.1016/j.appdev.2004.08.004.

Grant, A., \& Gino, F. (2010). A little thanks goes a long way: Explaining why gratitude expressions motivate prosocial behavior. Journal of Personality and Social Psychology, 98(6), 946-955. doi:10.1037/a0017935.

Guastello, S. J., Koopmans, M., \& Pincus, D. (2008). Chaos and complexity in psychology: The theory of nonlinear dynamical systems. New York: Cambridge University Press.

Gulliford, L., Morgan, B., \& Kristjánsson, K. (2013). Recent work on the concept of gratitude in philosophy and psychology. The Journal of Value Inquiry, 47(3), 285-317. doi:10.1007/s10790-013-9387-8.

Haidt, J., \& Keltner, D. (2003). Approaching awe, a moral, spiritual, and aesthetic emotion. Cognition and Emotion, 17(2), 297-314. doi:10.1080/02699930302297.

Hurley, D. B., \& Kwon, P. (2013). Savoring helps most when you have little: Interaction between savoring the moment and uplifts on positive affect and satisfaction with life. Journal of Happiness Studies, 14(4), 1261-1271. doi:10.1007/ s10902-012-9377-8.

Kashdan, T. B., Uswatte, G., Steger, M. F., \& Julian, T. (2006). Fragile self-esteem and affective instability in posttraumatic stress disorder. Behaviour Research and Therapy, 44(11), 1609-1619. doi:10.1016/j.brat.2005.12.003. 
Koo, M., Algoe, S. B., Wilson, T. D., \& Gilbert, D. T. (2008). It's a wonderful life: Mentally subtracting positive events improves people's affective states, contrary to their affective forecasts. Journal of Personality and Social Psychology, 95(5), 1217-1224. doi:10.1037/a0013316.

Krippendorff, K. (2013). Content analysis: An introduction to its methodology (3rd ed.). Thousand Oaks: SAGE Publications.

Lambert, N. M., Clark, M. S., Durtschi, J., Fincham, F. D., \& Graham, S. M. (2010). Benefits of expressing gratitude: Expressing gratitude to a partner changes one's view of the relationship. Psychological Science, 21(4), 574-580. doi:10.1177/0956797610364003.

Lambert, N. M., \& Fincham, F. D. (2011). Expressing gratitude to a partner leads to more relationship maintenance behavior. Emotion, 11(1), 52-60. doi:10.1037/a0021557.

Lambert, N. M., Fincham, F. D., \& Stillman, T. F. (2012). Gratitude and depressive symptoms: The role of positive reframing and positive emotion. Cognition and Emotion, 26(4), 615-633. doi:10.1080/02699931.2011.595393.

Lambert, N. M., Fincham, F. D., Stillman, T. F., \& Dean, L. R. (2009a). More gratitude, less materialism: The mediating role of life satisfaction. The Journal of Positive Psychology, 4(1), 32-42. doi:10.1080/17439760802216311.

Lambert, N. M., Graham, S. M., \& Fincham, F. D. (2009b). A prototype analysis of gratitude: Varieties of gratitude experiences. Personality and Social Psychology Bulletin, 35(9), 1193-1207. doi:10.1177/0146167209338071.

Lambert, N. M., Graham, S. M., Fincham, F. D., \& Stillman, T. F. (2009c). A changed perspective: How gratitude can affect sense of coherence through positive reframing. The Journal of Positive Psychology, 4(6), 461-470. doi:10.1080/17439760903157182.

Lies, J., Mellor, D., \& Hong, R. Y. (2014). Gratitude and personal functioning among earthquake survivors in Indonesia. The Journal of Positive Psychology, 9(4), 295-305. doi:10.1080/17439760.2014.902492.

Lin, C.-C., \& Yeh, Y.-C. (2014). How gratitude influences well-being: A structural equation modeling approach. Social Indicators Research, 118(1), 205-217. doi:10.1007/s11205-013-0424-6.

Loo, J. M. Y., Tsai, J.-S., Raylu, N., \& Oei, T. P. S. (2014). Gratitude, hope, mindfulness and personal-growth initiative: Buffers or risk factors for problem gambling? PLoS One, 9(2), 1-11. doi:10.1371/journal.pone.0083889.

Lyubomirsky, S., \& Layous, K. (2013). How do simple positive activities increase well-being? Current Directions in Psychological Science, 22(1), 57-62. doi:10.1177/0963721412469809.

McCullough, M. E. (2002). Savoring life, past and present: Explaining what hope and gratitude share in common. Psychological Inquiry, 13(4), 302-304. doi:10.2307/1448873.

McCullough, M. E., Emmons, R. A., \&Tsang, J.-A. (2002). The grateful disposition: A conceptual and empirical topography. Journal of Personality and Social Psychology, 82(1), 112-127. doi:10.1037/0022-3514.82.1.112.

McCullough, M. E., Root, L. M., \& Cohen, A. D. (2006). Writing about the benefits of an interpersonal transgression facilitates forgiveness. Journal of Consulting and Clinical Psychology, 74(5), 887-897. doi:10.1037/0022-006X.74.5.887.

McGraw, K. O., \& Wong, S. P. (1996). Forming inferences about some intraclass correlation coefficients. Psychological Methods, 1(1), 30-46. doi:10.1037/1082-989x.1.1.30.

Mikulincer, M., Shaver, P. R., \& Slav, K. (2006). Attachment, mental representations of others, and gratitude and forgiveness in romantic relationships. In M. Mikulincer \& G. S. Goodman (Eds.), Dynamics of romantic love: attachment, caregiving, and sex (pp. 190-215). New York, NY: Guilford Press.

Neto, F. (2007). Forgiveness, personality and gratitude. Personality and Individual Differences, 43(8), 2313-2323. doi:10.1016/j.paid.2007.07.010

Nolen-Hoeksema, S., Wisco, B. E., \& Lyubomirsky, S. (2008). Rethinking rumination. Perspectives on Psychological Science, 3(5), 400-424. doi:10.1111/j.1745-6924.2008.00088.x.

Ouellette, J. A., \&Wood, W. (1998). Habit and intention in everyday life: The multiple processes by which past behavior predicts future behavior. Psychological Bulletin, 124(1), 54-74. doi:10.1037/0033-2909.124.1.54.

Peterson, C., Park, N., \& Seligman, M. E. (2005). Assessment of character strengths. In G. P. Koocher, J. C. Norcross, \& S. S. Hill III (Eds.), Psychologists' desk reference (2nd ed., pp. 93-98). New York: Oxford University Press.

Pinquart, M., \& Forstmeier, S. (2012). Effects of reminiscence interventions on psychosocial outcomes: A meta-analysis. Aging and Mental Health, 16(5), 541-558. doi:10.1080/13607863.2011.651434.

Polak, E. L., \& McCullough, M. E. (2006). Is gratitude an alternative to materialism? Journal of Happiness Studies, 7(3), 343-360. doi:10.1007/s10902-005-3649-5.

Proyer, R. T., Ruch, W., \& Buschor, C. (2013). Testing strengths-based interventions: A preliminary study on the effectiveness of a program targeting curiosity, gratitude, hope, humor, and zest for enhancing life satisfaction. Journal of Happiness Studies, 14(1), 275-292. doi:10.1007/s10902-012-9331-9.

Quoidbach, J., Berry, E. V., Hansenne, M., \& Mikolajczak, M. (2010). Positive emotion regulation and well-being: Comparing the impact of eight savoring and dampening strategies. Personality and Individual Differences, 49(5), 368-373. doi:10.1016/j.paid.2010.03.048.

Quoidbach, J., Wood, A. M., \& Hansenne, M. (2009). Back to the future: The effect of daily practice of mental time travel into the future on happiness and anxiety. The Journal of Positive Psychology, 4(5), 349-355. doi:10.1080/17439760902992365.

Rey, D. (2009). The relationship of gratitude and subjective well-being to self-efficacy and control of learning beliefs among college students. California: University of Southern California.

Rothaupt, J. W., \& Morgan, M. M. (2007). Counselors' and counselor educators' practice of mindfulness: A qualitative inquiry. Counseling and Values, 52(1), 40-54. doi:10.1002/j.2161-007X.2007.tb00086.x.

Ruini, C., \&Vescovelli, F. (2013). The role of gratitude in breast cancer: Its relationships with post-traumatic growth, psychological well-being and distress. Journal of Happiness Studies, 14(1), 263-274. doi:10.1007/s10902-012-9330-x.

Rusk, R. D., \&Waters, L. E. (2013). Tracing the size, reach, impact, and breadth of positive psychology. The Journal of Positive Psychology, 8(3), 207-221. doi:10.1080/17439760.2013.777766.

Rusk, R. D., \&Waters, L. (2015). A psycho-social system approach to well-being: Empirically deriving the five domains of positive functioning. The Journal of Positive Psychology, 10(2), 141-152. doi:10.1080/17439760.2014.920409.

Seligman, M. E. P., Steen, T. A., Park, N., \& Peterson, C. (2005). Positive psychology progress: Empirical validation of interventions. American Psychologist, 60(5), 410-421. doi:10.1037/0003-066X.60.5.410. 
Sheldon, K. M., \& Lyubomirsky, S. (2006). How to increase and sustain positive emotion: The effects of expressing gratitude and visualizing best possible selves. The Journal of Positive Psychology, 1(2), 73-82. doi:10.1080/17439760500510676.

Simão, C., \& Seibt, B. (2014). Gratitude depends on the relational model of communal sharing. PLoS One, 9(1), e86158. doi:10.1371/journal.pone.0086158.

Smith, R. H. (2000). Assimilative and contrastive emotional reactions to upward and downward social comparisons. In J. Suls \& L. Wheeler (Eds.), Handbook of social comparison: Theory and research (pp. 173-200). New York: Springer.

Tedeschi, R. G., \& Calhoun, L. G. (1996). The posttraumatic growth inventory: Measuring the positive legacy of trauma. Journal of Traumatic Stress, 9(3), 455-471. doi:10.1007/BF02103658.

Teigen, K. H. (1997). Luck, envy and gratitude: It could have been different. Scandinavian Journal of Psychology, 38(4), 313-323. doi:10.1111/1467-9450.00041.

Thomas, M. \& Watkins, P. (2003). Measuring the grateful trait: Development of the revised GRAT. In Poster session presented at the Annual Convention of the Western Psychological Association, Vancouver, BC.

Toussaint, L., \& Friedman, P. (2009). Forgiveness, gratitude, and well-being: The mediating role of affect and beliefs. Journal of Happiness Studies, 10(6), 635-654. doi:10.1007/s10902-008-9111-8.

Tsang, J.-A. (2006). Gratitude and prosocial behaviour: An experimental test of gratitude. Cognition and Emotion, 20(1), 138-148. doi:10.1080/02699930500172341.

Tsang, J.-A., Rowatt, W. C., \& Buechsel, R. K. (2008). Exercising gratitude. In S. J. Lopez (Ed.), Positive psychology: Exploring the best in people (Vol. 2, pp. 37-53). Westport: Greenwood Publishing Company.

Tucker, K. L. (2007). Getting the most out of life: An examination of appreciation, targets of appreciation, and sensitivity to reward in happier and less happy individuals. Journal of Social and Clinical Psychology, 26(7), 791-825. doi:10.1521/ jscp.2007.26.7.791.

Vallacher, R. R., Coleman, P. T., Nowak, A., \& Bui-Wrzosinska, L. (2010). Rethinking intractable conflict: The perspective of dynamical systems. American Psychologist, 65(4), 262-278. doi:10.1037/a0019290.

Watkins, P. C. (2014). Gratitude and the good life: Toward a psychology of appreciation. Dordrecht: Springer.

Watkins, P. C., Cruz, L., Holben, H., \& Kolts, R. L. (2008). Taking care of business? Grateful processing of unpleasant memories. The Journal of Positive Psychology, 3(2), 87-99. doi:10.1080/17439760701760567.

Watkins, P. C., Grimm, D. L., \& Kolts, R. (2004). Counting your blessings: Positive memories among grateful persons. Current Psychology, 23(1), 52-67. doi:10.1007/s12144-004-1008-z.

Watkins, P. C., Van Gelder, M., \& Frias, A. (2009). Furthering the science of gratitude. In C. R. Snyder \& S. J. Lopez (Eds.), Oxford handbook of positive psychology (2nd ed., pp. 437-445). New York: Oxford University Press.

Watkins, P. C., Woodward, K., Stone, T., \& Kolts, R. L. (2003). Gratitude and happiness: Development of a measure of gratitude, and relationships with subjective well-being. Social Behavior and Personality, 31(5), 431-452. doi:10.2224/ sbp.2003.31.5.431.

Webb, T. L., \& Sheeran, P. (2006). Does changing behavioral intentions engender behavior change? A meta-analysis of the experimental evidence. Psychological Bulletin, 132(2), 249-268. doi:10.1037/0033-2909.132.2.249.

Weiner, B., \& Graham, S. (1989). Understanding the motivational role of affect: Life-span research from an attributional perspective. Cognition and Emotion, 3(4), 401-419. doi:10.1080/02699938908412714.

Wood, A. M., Froh, J. J., \& Geraghty, A. W. (2010). Gratitude and well-being: A review and theoretical integration. Clinical Psychology Review, 30(7), 890-905. doi:10.1016/j.cpr.2010.03.005.

Wood, A. M., Joseph, S., \& Linley, P. A. (2007). Coping style as a psychological resource of grateful people. Journal of Social and Clinical Psychology, 26(9), 1076-1093. doi:10.1521/jscp.2007.26.9.1076.

Wood, A. M., Joseph, S., \& Maltby, J. (2008). Gratitude uniquely predicts satisfaction with life: Incremental validity above the domains and facets of the five factor model. Personality and Individual Differences, 45(1), 49-54. doi:10.1016/j. paid.2008.02.019.

Wood, A. M., Joseph, S., \& Maltby, J. (2009). Gratitude predicts psychological well-being above the Big Five facets. Personality and Individual Differences, 46(4), 443-447. doi:10.1016/j.paid.2008.11.012.

Yip, J. J., \& Kelly, A. E. (2013). Upward and downward social comparisons can decrease prosocial behavior. Journal of Applied Social Psychology, 43(3), 591-602. doi:10.1111/j.1559-1816.2013.01039.x.

\section{Submit your manuscript to a SpringerOpen ${ }^{\circ}$ journal and benefit from:}

- Convenient online submission

- Rigorous peer review

- Immediate publication on acceptance

- Open access: articles freely available online

- High visibility within the field

- Retaining the copyright to your article

Submit your next manuscript at $>$ springeropen.com 